This document was prepared in conjunction with work accomplished under Contract No. DE-AC09-96SR18500 with the U.S. Department of Energy.

This work was prepared under an agreement with and funded by the U.S. Government. Neither the U. S. Government or its employees, nor any of its contractors, subcontractors or their employees, makes any express or implied: 1 . warranty or assumes any legal liability for the accuracy, completeness, or for the use or results of such use of any information, product, or process disclosed; or 2 . representation that such use or results of such use would not infringe privately owned rights; or 3 . endorsement or recommendation of any specifically identified commercial product, process, or service. Any views and opinions of authors expressed in this work do not necessarily state or reflect those of the United States Government, or its contractors, or subcontractors. 


\title{
ESTIMATING FATE AND TRANSPORT OF MULTIPLE CONTAMINANTS IN THE VADOSE ZONE USING A MULTI-LAYERED SOIL COLUMN AND THREE-PHASE EQUILIBRIUM PARTITIONING MODEL
}

\author{
Gregory G. Rucker, B.S., M.S. \\ Senior Advisory Engineer \\ 730-4B, Room 3043 \\ Washington Savannah River Company \\ Aiken, South Carolina 29808 \\ gregory.rucker@srs.gov \\ 803-952-6683
}

\begin{abstract}
Soils at waste sites must be evaluated for the potential of residual soil contamination to leach and migrate to the groundwater beneath the disposal area. If migration to the aquifer occurs, contaminants can travel vast distances and contaminate drinking water wells, thus exposing human receptors to harmful levels of toxins and carcinogens. To prevent groundwater contamination, a contaminant fate and transport analysis is necessary to assess the migration potential of residual soil contaminates. This type of migration analysis is usually performed using a vadose zone model to account for complex geotechnical and chemical variables including: contaminant decay, infiltration rate, soil properties, vadose zone thickness, and chemical behavior.
\end{abstract}

The distinct advantage of using a complex model is that less restrictive, but still protective, soil threshold levels may be determined avoiding the unnecessary and costly remediation of marginally contaminated soils. However, the disadvantage of such modeling is the additional cost for data collection and labor required to apply these models. In order to allay these higher costs and to achieve a less restrictive but still protective clean-up level, a multiple contaminant and multi layered soil column equilibrium partitioning model was developed which is faster, simpler and less expensive to use.

\section{NOMENCLATURE}

Action Level $(A L)$ - a statutory or risk-based drinking water concentration with units of $\mathrm{pCi} / \mathrm{L}$ (picocuries per liter) for radionuclides or $\mu \mathrm{g} / \mathrm{L}$ (micrograms per liter) for all chemicals and metals.

Aqueous Solubility (S) mg/L (milligrams per liter).

Aquifer Thickness $\left(d_{a}\right)$ m (meters)

b Parameter - Exponential value empirically fit to soil moisture characteristic curve to account for a discontinuity in suction near saturation, dimensionless.

Decay Adjusted Soil Threshold Level $\left(S_{T} L_{T 1 / 2}\right), p C i / g$ (picocuries per gram) for radionuclides or $\mathrm{mg} / \mathrm{kg}$ (milligrams per kilogram) for chemicals and metals.

Dilution Attenuation Factor (DAF) - A dimensionless value that describes the dilution and mixing in the aquifer.

Effective Moisture Content $\left(\theta_{\mathrm{e}}\right)$ - A representation of the available porosity that will support flow and excludes disconnected pore space, L/L (liter/liter), \%.

Effective porosity $\left(n_{e}\right) L / L, \%$.

Evaluation Time (Te) (years)

Exposure Duration (ED) - (years) 
Groundwater Concentration $\left(\mathrm{C}_{\mathrm{gw}}\right)-\mathrm{pCi} / \mathrm{L}$ for radionuclides and $\mu \mathrm{g} / \mathrm{L}$ for chemicals and metals.

\section{Henry's Law Constant $(\mathrm{H})$ dimensionless.}

Horizontal Hydraulic Gradient (i) $\mathrm{m} / \mathrm{m}$, (meter/meter).

Infiltration Rate (I) m/yr (meters per year).

Length of Source Parallel to Flow (L) (meters).

Length Vertical $\left(L_{v}\right)$ - distance from bottom of source layer to top of the water table, (meters)

Mean Travel Time $\left(T_{\text {Mean }}\right)$ - the average time for unsaturated flow to travel from the bottom of source layer to top of the water table, (years).

Mixing Zone Depth (d) meters.

Pore-water Velocity in vadose zone $\left(V_{s}\right)$, meters/year.

Radioactive Half-life $\left(T_{1 / 2}\right)$ radioisotope specific value (years).

Retardation (R) - A calculated value that retards the pore-water velocity and is dimensionless.

Saturated Hydraulic Conductivity $\left(\mathrm{K}_{\mathrm{s}}\right)$ meters/year.

Soil-water Distribution Coefficient $\left(\mathrm{K}_{\mathrm{d}}\right) \mathrm{L} / \mathrm{kg}$ (liters per kilogram).

Soil Bulk Density $(\rho \beta) \mathrm{kg} / \mathrm{L}$ (kilograms per liter).

Soil Threshold Level (STL) - the concentration in soil below which there is no potential for a chemical, metal or radionuclide to migrate to groundwater.

Total porosity $\left(n_{t}\right)$ L/L \%.

Total Soil Concentration $\left(C_{t}\right)-m g / k g$ for chemicals and $\mathrm{pCi} / \mathrm{g}$ for radionuclides.
Vadose Zone Contaminant Migration MultiLayered Model $^{\odot} \quad\left(\mathrm{VZCOMML}^{\odot}\right)^{-}$ Pronounced V-Z-Com.

Volumetric Moisture Content $\left(\theta_{\mathrm{w}}\right), \mathrm{L} / \mathrm{L}, \%$.

\section{REVIEW OF MODEL FUNDAMENTALS}

$\mathrm{VZCOMML}^{\odot}$ is a one-dimensional, steadystate, equilibrium partitioning vadose zone model that uses a multi-layered soil column. The model's objectives are to: 1) perform robust fate and transport analyses, that will comply with requirements imposed by the Comprehensive Response Compensation and Liability Act (CERCLA), for residual concentrations of soil contaminants; 2) calculate less restrictive, but still protective soil threshold levels and clean-up goals; and 3 ) allow the user to evaluate the effectiveness of certain remedial alternatives by altering hydrogeological properties such as the infiltration rate and time affects. The model operates in a spreadsheet architecture using Microsoft Excel ${ }^{\odot}$ software which is universally available in a variety of languages and operating systems.

The model is unique in that it will analyze the fate and transport potential for over 193 radionuclides and chemicals during a single simulation. The model incorporates the impact of both radiological decay of radionuclides and biodegradation of chemicals over time. Mean travel time is calculated using Darcy's Law for flow in porous media. The model is designed to be pre-loaded with geotechnical, radiological and chemical-specific properties to mimic on-site conditions. These variables only need to be changed for "fine tuning" purposes, but otherwise can remain unchanged as long as site-specific conditions remain unchanged.

The model is a combination of independent analytical modules whose outputs are linked to the numerical outputs of all the other modules. There are four distinct modules. The dilution attenuation factor (DAF) and mixing zone parameters are calculated using analytical equations and comprise a simple one dimensional water balance. The pore-water velocity module solves vadose zone pore-water velocity, air-filled porosity, 
water filled porosity, moisture content, and unretarded travel time through a four layered soil column. Hydrogeologic properties, including hydraulic conductivity, layer thicknesses, total porosity, and effective porosity are user defined and assembled into the heterogeneous soil column. The solution for solving pore-water velocity is unique and relates the soil moisture content to suction head and constructs a "soil-water characteristic curve" with a power function from the work of Clapp and Hornberger [1].

The screening module automatically screens total contaminant concentrations from the waste unit source area against soil threshold concentrations and a Soil Saturation Limit for single component non-aqueous phase liquid (NAPL) which may be present in soils.

The result module is the most sophisticated component of the model. It interprets the numerical output using automated logic criteria to determine if there is a contaminant migration potential based on time and concentrations. Three logic criteria are used for the interpretation: 1) comparison of the groundwater concentrations to an action limit; 2) comparison of the retarded, mean travel time of the contaminants to reach the aquifer to a user defined time limit, and 3) comparison of the waste site soil concentrations to a mass-limited and an infinite source soil threshold concentration. Results are in the form of Soil Threshold Concentrations below which, there is no possibility of the contaminant migrating to groundwater. Contaminants failing the evaluation are automatically indicated for the user. This module also lists the retardation coefficient, mean travel time, groundwater concentration, decay-adjusted mass-limited soil threshold value, and infinite source soil threshold value for each contaminant. There is no run-time for simulations and the results are computed instantaneously when the inputs are provided.

The model has also been designed to require a modicum of simple, easily obtained geotechnical data and does not require esoteric or experiment data inputs

\section{MODEL ASSUMPTIONS}

The calculations simulate dispersive mixing in the saturated zone and three phase equilibrium partitioning in the contaminated zone. Both a homogeneously distributed infinite and mass-limited source is conservatively assumed in the source zone layer for leaching estimates. All radioactive decay and biodegradation are calculated using a first-order reaction. The model can be used with the decay/biodegradation function either enabled or disabled. The following summarizes major model assumptions:

- The source layer is considered to be an infinite source, but is also treated as a mass-limited source to avoid mass balance discontinuities.

- The system is at equilibrium with respect to adsorption.

- Adsorption is linear with concentration (a nonlinear isotherm is not used.)

- Contaminants are homogeneously distributed in the source zone.

- The receptor drinking water well is adjacent to the edge of the waste site. This is a conservative assumption to ensure the results are protective of human health.

Figure 1 illustrates the conceptual framework of the model.

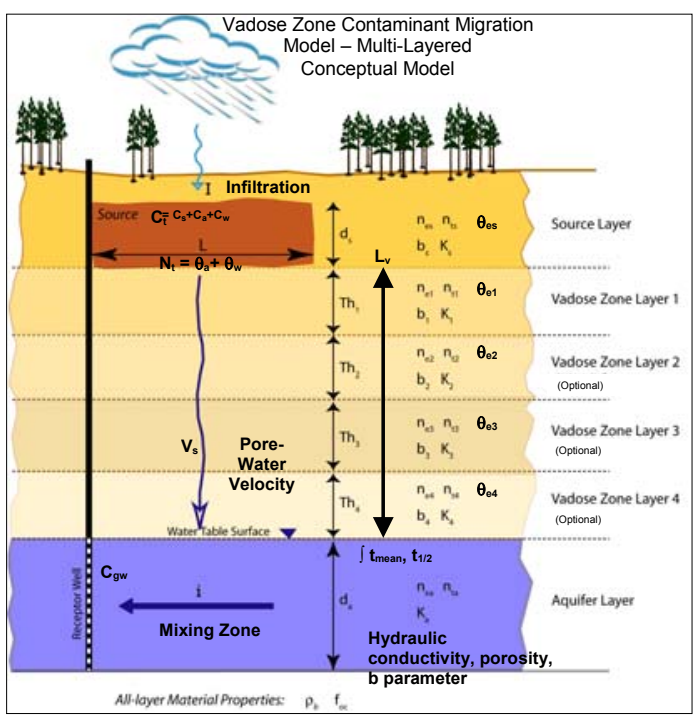


Figure 1. VZCOMML ${ }^{\odot}$ Conceptual Model

\section{MIXING ZONE AND DILUTION ATTENUATION FACTOR}

As contaminants migrate downwards in the vadose and eventually into the aquifer, their concentrations become both attenuated and diluted due to mixing with the pore-water and groundwater. A simple hydrogeological water-balance relationship and mixing zone equation are included in the model to simulate this mechanism. Equation (1) is the mixing zone equation and Eq. (2) is the dilution factor equation.

$$
\begin{aligned}
& d=\left(0.0112 \cdot L^{2}\right)^{0.5} \\
& +d_{a} \cdot\left(1-e^{\left((-L \cdot I) / K_{\text {s. } \cdot d_{a}}\right)}\right) \\
& D F=1+\frac{K_{s} \cdot i \cdot d}{I \cdot L}
\end{aligned}
$$

\section{PORE-WATER VELOCITY AND TRAVEL TIME}

Mean travel time is an important parameter since it determines the time to allow for decay in the equilibrium algorithms and also has bearing on the relative certainty of the transport estimations. Pore-water velocity and mean travel time are estimated by the model using sequential equations.

Freeze and Cherry [2] have stated hydraulic conductivity in the vadose zone is a function of water content such that $\mathrm{K}_{\mathrm{s}}=\mathrm{K}_{\mathrm{s}}(\theta)$. The unretarded pore-water velocity determined from Eqs. 3, 4, and 5 use the "soil moisture characteristic" to calculate the water content of a soil type as developed by Clapp and Hornberger [3]. This method allows the pore-water velocity to be determined as the ratio of infiltration and the volumetric water content from the US Environmental Protection Agencty 1988 [4].

$$
\theta_{w}[\%]=n_{t} \cdot\left(\frac{I}{K_{s}}\right)^{\left(\frac{1}{(2 b+3)}\right)}
$$

$$
\begin{aligned}
& \theta_{e}[\%]=\theta_{w} \cdot \frac{n_{e}}{n_{t}} \\
& V_{s}[\mathrm{~m} / \text { year }]=\frac{I}{\theta_{e}}
\end{aligned}
$$

The pore-water velocity $\left(V_{s}\right)$ is then used to calculate the mean travel time $\left(\mathrm{T}_{\text {Mean }}\right)$ in the vadose zone by the following equation:

$$
T_{\text {Mean }}[\text { years }]=\frac{L_{v} \cdot R}{V_{s}}
$$

In Eq. (6) the term $\left(L_{v}\right)$ actually represents the sum of the layer thicknesses $\left(\sum T h_{1,2,3,4}\right)$ in the multi-layered soil column and is the distance measured from the bottom of the contaminated zone to the top of the water table and with units of meters $(\mathrm{m})$. The term $(R)$ is the retardation coefficient for vadose zone soils and is dimensionless.

$$
R=1+\frac{\left(K_{d} \cdot \rho \beta\right)}{\theta_{e}}
$$

\section{EQUILIBRIUM PARTITIONING}

The model estimates soil and groundwater concentrations with the use of equilibrium algorithms. Due to the number of chemical classes (volatile organics, semi-volatile organics, radionuclides, metals, volatile metals, pesticides) included in the model there are a variety of two and three phase equilibrium algorithms that are used to calculate media concentrations. Since it is beyond the scope of this paper to present all the equations only a few governing equations will be selected as examples.

Because of the conservation of mass, the partitioning of a compound into each of three media phases $\left(M_{a}\right.$ - mass in vapor phase, $M_{s}$ - mass in solid phase, and $M_{w}$ mass in liquid phase) must balance with the total contaminant mass of the sample $\mathrm{M}_{\mathrm{t}}$. This is expressed by the following equation from Feenstra, et al [5]:

$$
M_{t}=M_{a}+M_{w}+M_{s}
$$


A reversible linear isotherm is used for contaminant partitioning in the source zone and is represented by the soil-water distribution coefficient $\left(\mathrm{K}_{\mathrm{d}}\right)$ for liquid-solid phases and Henry's Law Constant $(\mathrm{H})$ for liquid-vapor phases. The Henry's Law Constants used in the model are appropriate values found published in scientific literature from the United States Environmental Protection Agency (USEPA) 1996 [6], etc. The soil-water distribution coefficients arise from two sources: 1) in the case of radionuclides and metals, appropriate values were selected from scientific publications such as referenced above, and 2) for organic chemicals, the model calculates the partitioning coefficient according to the following equation where $\mathrm{K}_{\mathrm{oc}}$ is the soil organic carbon/water partition coefficient $(\mathrm{L} / \mathrm{kg})$ and $\mathrm{f}_{\mathrm{oc}}$ is the fraction of organic carbon in soil (gram/gram, \%):

$$
K_{d}=f_{o c} \cdot K_{o c}
$$

A linear form of the Freundlich isotherm is used to estimate $C_{t}$, the total soil concentration, USEPA 1996 [7] in Eq. (10). The complete three phase equilibrium algorithm appears as:

$$
C_{t}[\mathrm{mg} / \mathrm{kg}]=C_{g w} \cdot\left(K_{d} \cdot \frac{\theta_{w}+\theta_{a} \cdot H}{\rho \beta}\right)
$$

For estimating groundwater concentrations, the terms in Eq. (10) are rearranged to yield Eq. (11). For radionuclides and organic chemicals, a first order decay term is added. The final leachate concentration is then divided by the DAF because of dilution and mixing in the aquifer. Equation (11) is for radionuclides in groundwater and is two phase, since there is no contaminant mass associated with the vapor phase.

$$
C_{g w}[p C i / L]=\frac{\left(C_{t} \cdot[1000 \mathrm{~g} / \mathrm{kg}] \cdot e^{\left(-0.693 \cdot T_{\text {Mean }} / T_{1 / 2}\right)}\right)}{K_{d}+\frac{\theta_{w}}{\rho \beta}} / D A F
$$

Equation (12) illustrates the three phase equilibrium algorithm for mercury. For metals a first order decay term is not included since the half-life of a metal analyte is treated as infinite.

$$
C_{g w}[\mu g / L]=\frac{C_{t} \cdot[1000 \mu g / m g]}{\left(K_{d}+\frac{\theta_{w}+H \cdot \theta_{a}}{\rho \beta}\right)} / D A F
$$

The model will screen soil contaminant concentrations for the presence of nonaqueous phase liquids (NAPLs). NAPLs can impose challenges for waste site remediation, especially if its presence is not recognized. Hence, it is the reason NAPL screening is included in the model. From the work of Feenstra, et al, [8] the model calculates a Soil Saturation Limit $\left(\mathrm{C}_{\text {sat }}\right)$ in Eq. (13) which is an upper boundary limit that corresponds to a soil concentration at which the absorptive limits of the soil, the solubility limits of the pore-water, and the saturation of pore-air have been reached. Above this concentration, a NAPL may be present in the soil. For further information on the method for determination and quantification of NAPL mixtures in soils, refer to Rucker 2006 [9].

$$
C_{\text {sat }}[\mathrm{mg} / \mathrm{kg}]=\frac{S}{\rho \beta} \cdot\left(K_{d} \cdot \rho \beta+\theta_{w}+H \cdot \theta_{a}\right)
$$

One of the most important values calculated by the model is the Soil Threshold Level (STL). The STL is a soil concentration, below which there is no possibility for the contaminant to migrate to groundwater. There are several methods to calculate STLs. The $\mathrm{VZCOMML}^{\circ}$ model uses an approach that ensures protectiveness of drinking water sources, but is not as conservative as some of the alternative methods. Therefore, VZCOMML ${ }^{\circledR}$ can calculate a less restrictive STL, while providing a protective clean-up level. Synonymously, the STL calculated in the model may be considered as a soil remedial goal or as soil clean up value that is protective of drinking water.

The model ensures protectiveness using the assumptions previously mentioned in the paper. The assumption of an infinite source is conservative in nature since, in reality, all sources are finite. The assumption of a receptor drinking water well adjacent to the edge of the waste site is also very conservative and only allows minimal dilution and mixing of leachate concentrations. 
Equation (14) illustrates a degradationadjusted STL for a volatile organic compound. This algorithm is based on an infinite source.

$S T L_{1 / 2}[\mathrm{mg} / \mathrm{kg}]=A L \cdot D A F$

$x \frac{\left(K_{d}+\frac{\left(\theta_{w}+H \cdot \theta_{a}\right)}{\rho \beta}\right)}{e^{\left(-0.693 \cdot T_{\text {Mean }} / T_{1 / 2}\right)}} /[1000 \mu \mathrm{g} / \mathrm{mg}]$

For radionuclides, the pore-vapor term is deleted and a different conversion factor is applied because the result units are in $\mathrm{pCi} / \mathrm{g}$ as in Eq. (15).

$\operatorname{STL}_{1 / 2}[p C i / g]=A L \cdot D A F \cdot[0.00 \mathrm{~kg} / \mathrm{g}]$

$x \frac{\left(K_{d}+\frac{\theta_{w}}{\rho \beta}\right)}{e^{\left(-0.693 T_{\text {Mean }} / T_{1 / 2}\right)}}$

Eqs. 14 and 15 maybe too conservative if the contaminant mass of the waste site is small and the $\mathrm{K}_{\mathrm{d}}$ of the contaminants of concern are low. As previously mentioned, the model also incorporates a mass-limited scenario to avoid mass balance discontinuities. The mass-limited STL (MLSTL) is computed simultaneously with the finite source STL and the values of each are compared to one another. Therefore, to avoid the mass balance discontinuities the higher of the two STL values should be regarded as the appropriate soil clean up level. Both STLs are decay adjusted values, except for the metals. Equation (16) illustrates the mass-limited STL for radionuclides where $d_{s}$ is the depth of contamination beneath the source in meters and ED is the exposure duration which is time in years. The ED is user-defined in the model and may reflect the period of institutional controls, an average lifetime, the period of adulthood, or the length of time a human receptor could normally be expected to consume drinking water from a well.

$$
\begin{aligned}
& M L S T L[p C i / g]=\frac{(A L \cdot D A F \cdot I \cdot E D \cdot[0.001 \mathrm{~kg} / g])}{\left(\rho \beta \cdot d_{s}\right)} \\
& x \frac{1}{e^{\left(-0.093 \cdot E D / T_{1 / 2}\right)}}
\end{aligned}
$$

\section{AUTOMATED DECISION LOGIC}

The $\mathrm{VZCOMML}{ }^{\odot}$ model is designed to automatically interpret the numerical data that are computed. The decision criteria the software uses are referred to as logic arguments that are answered with a "True or False" response and are embedded into the model code. The logic criteria are very important for the user to understand because it serves as the technical basis for the decisions that the software generates.

The three logic criteria are:

1. Is the groundwater concentration greater than or equal to the Action Level or $\mathrm{C}_{\mathrm{gw}}>=\mathrm{AL}$ ?

2. Is the mean travel time less than or equal to the evaluation time $\left(T_{e}\right)$ or $\mathrm{T}_{\text {Mean }}<=\mathrm{T}_{\mathrm{e}}$ ?

3 . Is the waste site soil concentration greater than or equal to the mass limited soil threshold limit or $\mathrm{C}_{\mathrm{t}}>=\mathrm{MLSTL}$ ?

All of the above logic criteria are connected by an "and" operator rather than an "or" operator. This statement means the model must evaluate all the logic arguments "True" in order for a radionuclide or chemical to be of concern. Table I is a decision logic matrix and illustrates the model's interpretation of the logic criteria.

Table I: Decision Logic Matrix

\begin{tabular}{|l|l|l|l|l|l|l|l|l|}
\hline $\begin{array}{l}\text { Logic } \\
\text { Criteria }\end{array}$ & \multicolumn{7}{|c|}{ Permutations for Logic Arguments } \\
\hline $\mathrm{C}_{\mathrm{gw}}>=\mathrm{AL}$ & True & True & True & True & False & False & False & False \\
\hline $\mathrm{T}_{\text {Mean }}<=\mathrm{T}_{\mathrm{e}}$ & True & True & False & False & False & False & True & True \\
\hline $\mathrm{C}_{\mathrm{t}}>=\mathrm{MLSTT}$ & True & False & False & True & False & True & True & False \\
\hline Test Result & FAIL & Pass & Pass & Pass & Pass & Pass & Pass & Pass \\
\hline
\end{tabular}




\section{EXAMPLES OF MODEL OUTPUT}

The model generates robust numerical output. Table 2 lists some examples of the type of calculated results.

Table 2: Type of Results Calculated by the VZCOMML ${ }^{\circ}$ Model

\begin{tabular}{|c|}
\hline epth of mixing zone \\
\hline Dilution factor \\
\hline $\begin{array}{l}\text { Pore-water velocity for soil layers and } \\
\text { column }\end{array}$ \\
\hline Moisture content for soil layers and column \\
\hline Air-filled porosity \\
\hline Water-filled porosity \\
\hline $\begin{array}{l}\text { Unretarded mean travel time for each sc } \\
\text { layer and column }\end{array}$ \\
\hline Retardation coefficient \\
\hline Retarded mean travel time to groundwater \\
\hline Groundwater concentrations \\
\hline Decay-adjusted Soil Threshold Level \\
\hline $\begin{array}{l}\text { Mass-limited, decay adjusted Soil Thresho } \\
\text { Level }\end{array}$ \\
\hline 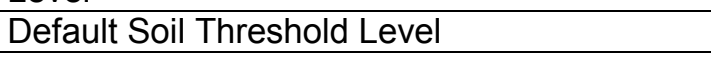 \\
\hline \\
\hline
\end{tabular}

The results of the model have been compared with other available models and the results have found to be in good agreement with both $\operatorname{RESRAD}^{\odot}$ and SESOIL ${ }^{\odot}$. Rucker 2002 [10] also documents that the model was at least two orders of magnitude (400 times) less conservative in calculating a higher, but still protective STL than the U.S. Environmental Protection Agency method for calculating soil screening levels.

\section{HYDROGEOLOGICAL SCENARIOS}

EVALUATION

The $\mathrm{VZCOMML}^{\odot}$ model has a limited capability to perform simple hydrogeological evaluation scenarios. This capability was used by the Savannah River Site (SRS) in order to evaluate the remedial performance of low permeability soil cover systems for radioactive seepage basin soils. Radioactive seepage basin soils were found to be contaminated with a variety of radionuclides which had accumulated after years of service from specific nuclear material manufacturing processes. Fate and transport analysis performed using the model identified that strontium-90 $\left({ }^{90} \mathrm{Sr}\right)$ was the only contaminant that was likely to migrate to the local unconfined aquifer within no more than 50 years and exceed human health risk-based concentrations.

Under this scenario the Environmental Protection Agency and the South Carolina Department of Environmental Control both required a remedial action to prevent ${ }^{90} \mathrm{Sr}$ from migrating from contaminated vadose zone soils to the groundwater and exceeding the human health action level.

One of the proposed remedies included the construction of a soil cover system over one of the basins to reduce the infiltration rate to $10^{-7}$ centimeter per second $(\mathrm{cm} / \mathrm{sec})$, thus reducing mass flux to the groundwater. Through engineering studies, it was discovered that the soil cover system would need to include a synthetic membrane layer to achieve that infiltration rate which significantly increased the cost of construction. Due to the excessive costs of constructing such a cover system, the questions were asked 1) if the cover system was over-designed, and 2) if it was overdesigned, what was the minimal infiltration rate allowable to still be protective of the groundwater action limit?

The model was used to perform this hydrogeological evaluation and it was determined that the proposed $10^{-7} \mathrm{~cm} / \mathrm{sec}$ infiltration rate was far in excess of the needed performance criteria. Simulations found that infiltration control over the seepage basin could be maintained with a $10^{-5} \mathrm{~cm} / \mathrm{sec}$ soil cover system and that this level of infiltration control could be provided with locally available soils thus eliminating the need for a synthetic membrane layer. This simple design change prevented the unnecessary outlay of significant capital costs for construction of the cover system.

\section{LIMITATIONS}

No attempt is made in the model to account for water flow in fractured bedrock or to account for facilitated flow (colloidal or preferential flow, etc.) in the vadose zone or 
aquifer. The effects of dispersion are ignored in the vadose zone to simplify the calculations; however, the effects of dispersion in the vadose zone are minimal. The infiltration rate cannot exceed the saturated hydraulic conductivity in vadose zone soils which results in a condition known as "ponding". The model does not accommodate "ponding" and the user will be warned by the model to modify the input data to avoid this condition. Additionally, the model does not perform transport time steps, but it does account for mean travel times. Moreover, the model is one-dimensional.

\section{CONCLUSION}

Use of this model can provide companies and governmental organizations with a consistent, economical approach to solving the question of whether residual contaminants in soil at waste sites will migrate to groundwater in the future. The results are logical, simple, and presented in an easy to understand format. All computations are documented and included in the software. The model is simple and economical to operate and estimates less restrictive, but still protective soil clean up levels. The model is a copyrighted work and has been marketed on a commercial basis in the United States. Additionally, the model has been sold to engineering and consulting companies, as well as, universities for work on environmental clean up projects and is currently being used by the Savannah River Site's Soil and Groundwater Program, Deactivation and Decommissioning Program, and the Savannah River National Laboratory.

\section{REFERENCES}

1. Clapp, R.B, and Hornberger, G.M., 1978, "Empirical Equations for Some Soil Hydraulic Properties", Water Resources Research, Vol. 14, No. 4, pages 601 to 604.

2. Freeze, R.A. and Cherry, J.A., 1979, Groundwater, Prentise-Hall, Inc, Englewood Cliffs, New Jersey 07632, pages 38 to 45 .

3. Clapp, R.B, and Hornberger, G.M., 1978, "Empirical Equations for Some Soil Hydraulic Properties", Water Resources Research, Vol. 14, No. 4, page 604.
4. United States Environmental Protection Agency, 1988, Superfund Exposure Manual, PB89-135859, pages 64 to 71.

5. Feestra, S., Mackay, D.M., Cherry, J.A., 1991, "A Method for Assessing Residual NAPL Based on Organic Chemical Concentrations in Soil Samples", Ground Water Monitoring and Remediation, Spring, pages 128 to 136.

6. United States Environmental Protection Agency, 1996, Soil Screening Guidance: Technical Background Document, EPA/540/R-95/128, pages 133 to 136.

7. United States Environmental Protection Agency, 1996, Soil Screening Guidance: Technical Background Document, EPA/540/R-95/128, pages 32 to 41.

8. Feestra, S., Mackay, D.M., Cherry, J.A., 1991, "A Method for Assessing Residual NAPL Based on Organic Chemical Concentrations in Soil Samples", Ground Water Monitoring and Remediation, Spring, pages 129.

9. Rucker, G. G., "Determination and Quantification of Non-aqueous Phase Liquid Mixtures in Environmental Media", http://www.osti.gov/bridge/purl.cover.jsp ?purl=/891996-xWaCN2/

10. Rucker, G. G., 2002, "Predicting Fate and Transport of Contaminants in the Vadose Zone Using a Soil Screening Model", National Conference on Environmental Science and Technology, Battelle Press, Columbus, Ohio, pages 163-171. 